\title{
POST-WAR DEMOGRAPHIC AND ECOLOGICAL SURVEY OF DOG POPULATIONS AND THEIR HUMAN RELATIONSHIPS IN SIERRA LEONE. (A CASE STUDY OF URBAN FREETOWN)
}

\author{
${ }^{1}$ Mr. Roland Suluku, ${ }^{2}$ Mr. Ibrahim Abu-Bakarr, ${ }^{2}$ Mr. Jonathan Johnny, ${ }^{3}$ Prof F. Jonsyn-Ellis \\ ${ }^{1}$ Department of Animal Science, Njala University, Sierra Leone \\ ${ }^{2}$ Department of Wildlife Management, Ecotourism and Biodiversity Conservation \\ Njala University, Sierra Leone \\ ${ }^{2}$ Department of Wildlife Management, Ecotourism and Biodiversity Conservation \\ Njala University, Sierra Leone \\ ${ }^{3}$ Department of Biological Sciences,School of Environmental Sciences \\ Njala University ,Sierra Leone.
}

Accepted $19^{\text {th }}$ March, 2012

\begin{abstract}
This research conducted on 900 dog-owning households randomly selected in urban Freetown investigated dog population and ecology, and how they relate with human populations, with regards to rabies. Pre-tested questionnaires designed according to World Health Organization standards were administered from Allen town in the east to Juba hills in the west. Area measurements using prescribed methods were done in the east, central and west of Freetown. Dog population was obtained by counting the number of dogs in the three clusters. Results obtained revealed an estimated total dog population of 13,246 with a ratio of $1: 14$ dogs to humans respectively., Life expectancy of dogs was 3-4 years, although some lived up to 7 years and above. More males were involved in dog rearing than females. Although $72 \%$ of dog owners are skilled income earners, however, $81 \%$ do not feed their dogs with canned food; hence $88 \%$ don't know the cost of feeding their dogs. Approximately, $44 \%$ of households allow their dogs to scavenge garbage dumps and to mix with other dogs. Most dogs $(77 \%)$ are owned by parents, mainly for security purposes, but $59 \%$ do not monitor or register their dogs with veterinary clinics and the Ministry of Health and Sanitation. Lack of care and attention accounted for $78 \%$ of dog mortality; hence dog owners need to pay closer attention in the management of their dogs to reduce the incidence of dog bites and rabies for a healthy co-existence with them.
\end{abstract}

KEYWORD: Dog, Survey, Questionnaire

\section{INTRODUCTION}

The relationship between man and dog Canis lupus familaris is multi-faceted dating as farback as 13000 years before the birth of Christ (Morey and Darcy, 2006). Originally, dogs provided food and companionship, and later, dogs assisted with other human activities including hunting, herding and transportation. As stated by Boris .M. Levinson, (1969a), humans initially domesticated the dog to meet their own psychological needs, assist in Labour and also provide food. Throughout history, the bond established between humans and dogs has elevated their position and contribution to society to include more service oriented functions including assisting the deaf and blind, detective work, search and rescue work (at sea and land), therapy dogs, war dogs and livestock guarding. Humans have manipulated the breeding lines of dogs for centuries to establish specific colors, sizes, and personality traits that have utilized for sporting events and exhibitions to demonstrate proficiency in agility, racing, and sledding. Domestic dogs have followed and continue to follow the migration of man and can be found in nearly every part of the world where human beings live. The purpose of keeping dogs varies within and across individual communities and can include companionship, transportation, security, food acquisition and religious beliefs (Hart La, 1995a).Man in turn provides protection, companionship and accommodation and a regular source of food for dogs. These mutual benefits have built a trusting relationship throughout history between dogs and people and ultimately have made life easier for both. (McGourty, 2002). In Sierra Leone, where $63 \%$ of the human population (National Statistics Sierra Leone, 2006) lives in rural areas, the major activity is subsistence farming. Here, dogs are used mainly for hunting. In urban areas of the country, dogs are mainly kept for guarding property. A few people in both rural and urban communities keep dogs for both companionship and as pets. Hunting dogs are used to deter pests from destroying crops, and acquiring bush meat for human consumption. Although many societies derive significant benefits from their associations with dogs, dogs can also pose significant public health risk to humans (Talan DA et al, 1999; Wandeler AI, Bingham J, 2000; Weiss HB 1998). The transmission of rabies virus from dogs to humans undoubtedly carries the most serious threat and severe consequences. Dogs are the most important reservoirs of rabies virus in many parts of the world, particularly in Africa south of the Sahara. No diagnostic or laboratory confirmation of rabies has being conducted in Sierra Leone after 1974, due to a lack of the necessary infrastructure. In many parts of the world, owned and unsupervised dogs have easy access to contaminated waste, which is fed to them by their owners, or which they find around slaughter houses or butcher markets. This free range scavenging exposes dogs to disease and they can become infected with parasites, such as Echinococcus granulose, and subsequently expose people to cystic echinococcosis (Ouhelli et al, 1997). As in other animals, dogs harbour a great variety of macro parasites, microorganisms and viruses. A large proportion of these infectious agents that are disseminated among, and carried by dogs, are also harmful to man. Daily interactions between unsupervised dogs, either during mating, casual interaction or playing, provide opportunities for rabies virus and other pathogens 
to be transferred to man and other animals (Wandeler et al, 1993). During the eleven year old civil war (1991-2002) in Sierra Leone, a large proportion of the human population was internally displaced. Whitfield J, (2003) confirmed that the war displaced nearly half of the population. Many people moved from rural areas to Freetown, increasing the population from one million $(1,000,000)$ to two million five hundred thousand $(2,500,000)$. This lead to high incidence of crime in the city compelling most residents to buy and rear dogs for security purposes. Koroma A.M, (2009) reported that analysis of police statistics between 1998 and 2006 showed a clear increase in the crime rate in Sierra Leone, with the western area, (Freetown), recording the highest number of incidents $(32,305)$,compared to the Eastern $(7,182)$, Northern $(9,503)$ and Southern $(4,019)$ provinces. This number dropped slightly in 2001 for the western area to 31,009. The overall effect of the increased crime rate and war was a net increase in human and dog population in urban Freetown that ultimately resulted in an increase in the number of garbage dumps, displaced human population and refugee camps in and around Freetown. The expanding garbage dumps, dilapidated and burned houses, and broken vehicles, became an ideal resting places for unsupervised dogs to reproduce and multiply, which acted as an incentive for owned dogs to join them. Weak implementation of government policy and little concern for dogs enabled them to establish their own territory where they lived freely among the human population. The evidence indicates that the relationship between man and dog, particularly in the capital, requires an in depth study, to examine the increasing dog population. The practical importance of collecting data on dog populations is a prerequisite for developing a strategy for animal disease control and vaccination campaigns and for ecological and epidemiological studies that could be replicated in other parts of the country. The objective of this research was to establish baseline demographic and ecological data of the dog population in Urban Freetown for use by public health and veterinary officers in planning rabies control programs, and to improve the relationship between man and dogs in Freetown, and the country as a whole. Further studies will be conducted in other regions to compare the results obtained.

\section{MATERIALS AND METHODS}

\section{STUDY AREA IN URBAN FREETOWN}

The survey was conducted in the Urban District of the Western area of Freetown in Sierra Leone, starting from Allen town in the east to Juba hills in the west. Because they are the politically demarcated boundary between the urban and rural district of Freetown, the study area was chosen because of the high number of reported cases of dog bites in police stations and treatment centers at veterinary clinics from these areas (personal interview). The western area is divided into two districts; (urban and rural) and the survey was conducted in the Greater District known as Urban Freetown. The sample area $(82 \mathrm{~km} 2)$, with a population of 746,000 people, was divided into three clusters (East $=449,479$, West $=245,749$ and Central $=69,256$ ) based on the 2004 population census conducted by National Central Statistics of Sierra Leone. A total of 900 households, 300 from each cluster owning dogs, were randomly selected. A short structured questionnaire, according to World Health Organization standards (WHO, 1999) were administered to every fifth house on a street within each cluster. If no dogs were found in that house or compound, the next fifth house was selected until all houses on the street are exhausted. These questions were pre-tested and found to be appropriate for the survey Three separate areas within each cluster were selected and the number of dogs counted.The number of dogs counted and the area measured was used to estate the number of dogs per sampled area. The figures obtained were projected against the actual population of sampled area to provide an estimate of the total number of dogs in the study area. Area measurement was accomplished using metric measuring tape, a ranging pole, and pegs. The average measured area was $0.13 \mathrm{~km} 2$. The human population in the measured area was confirmed by counting the number of persons present in the house hold or compound. The human population obtained in the measured area in each cluster was added and divided by the number of clusters to obtain the average human population in the measured area. The number of dogs in the measured area was also divided by three to obtain an average number of dogs in the sampled area. The average number of people divided by the average number of dogs gave an estimate of the ratio of dogs to humans in measured areas. Human density in sampled areas was obtained from (82 km2) estimated on a scale of $1: 125,000 \mathrm{~km}$ maps and the aggregate population was obtained from the 2004 Sierra Leone National Population Census. The data collected were analyzed using the Statistics Package for Social Scientist (SPSS). These were then presented in the form of tables, to enhance explanation of results.

\section{QUESTIONAIRE SURVEY}

The World Health Organizations standard was used as the basis for designing the rabies questionnaire for the house hold survey (WHO/WSPA1990).Respondents owning dogs were asked their names, age, sex and religion; their occupations and salary range. Households without dogs were not interviewed. All households interviewed were asked the names of the areas where they lived, number of years spent in locality, number of dependants and dogs owned. The 900 questionnaires administered were retrieved after the survey was conducted and were subsequently analyzed.

\section{DOG MANAGEMENT PRACTICES}

House hold information on dog habitats included: food, water and shelter, and dog management practices. House hold families owning dogs were asked if they fed their dogs, types of food given to the dogs and frequency of feeding. Respondents were also asked if dogs were fed from the family meal or dependent on it, and the presence of garbage dumps in the area. All respondents were asked about the methods they used to feed their dogs, and if their dogs had access to garbage dumps in and out of their compounds, and if dog owners used special feeding/eating plates. Households owning dogs were asked if they provided water for their animals on a daily basis, the type of water provided, if this water was provided in a drinking trough, and if they had streams or rivers in their vicinity. Respondents were also asked about the places where dogs are housed or slept,

How to Cite this Article: Mr. Roland Suluku, Mr. Ibrahim Abu-Bakarr, Mr. Jonathan Johnny, Prof F. Jonsyn-Ellis “Post-war Demographic and Ecological Survey of Dog Populations and Their Human Relationships in Sierra Leone. (A Case Study of Urban Freetown)" Science Journal of Agricultural Research \& Management, Volume 2012, Article ID sjarm-282, 7 Pages, 2012. doi: $10.7237 /$ sjarm/282 


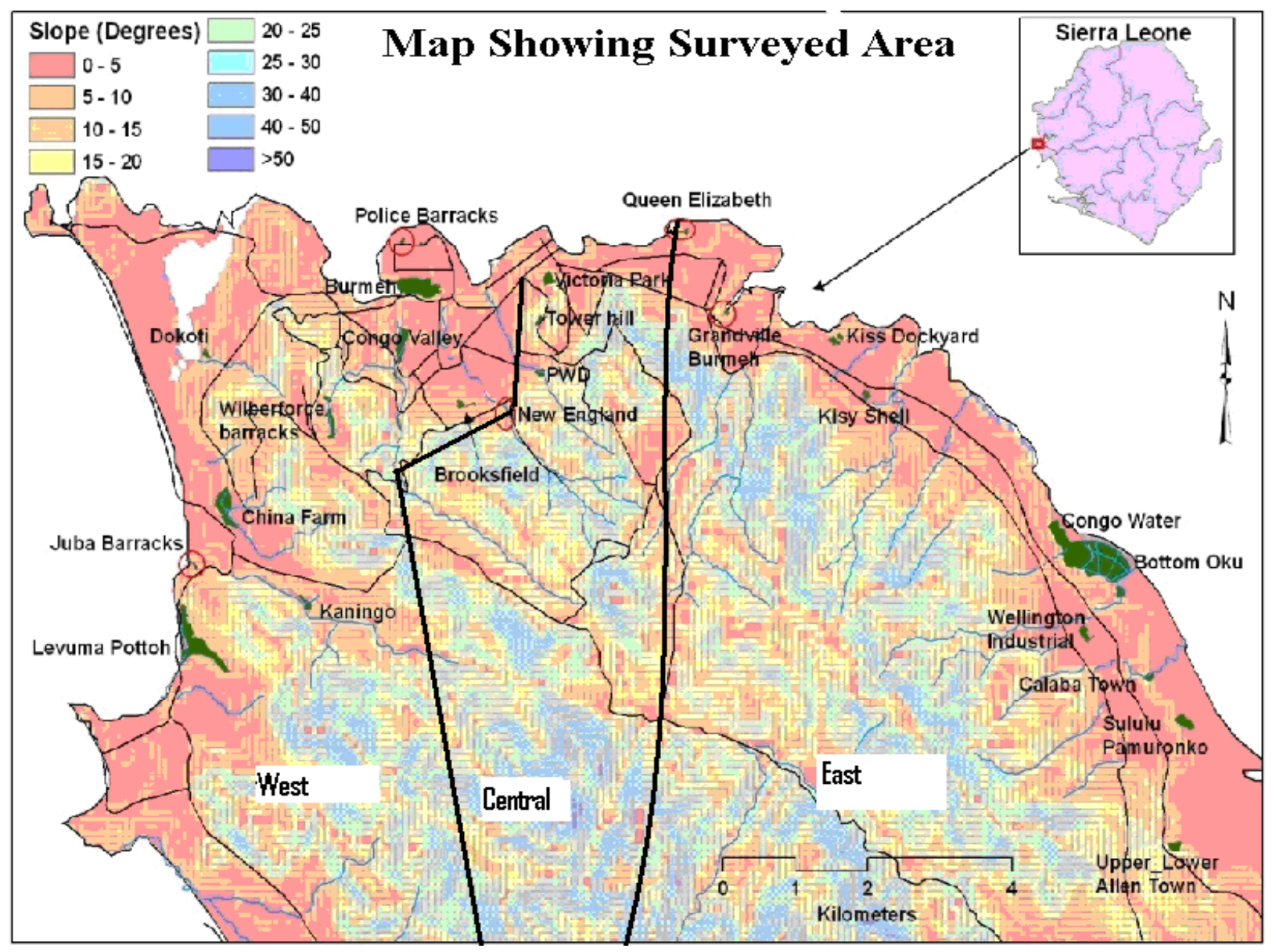

and if they provided sleeping places or shelter for their dogs. All were asked about the presence of unfinished houses and abandoned vehicles in the area. Surveyors were given 10 questionnaires each to administer to ten dog-owning family household in each section.

\section{INDIVIDUAL DOG DATA}

Dog-owning house hold families were asked which member of the family owned the dogs, the major purpose of rearing the dogs, if they were confined or fenced, how dogs were kept and how many puppies were produced per year, and the number of survivals and deaths per year. Additional information included the reproductive performance of female dogs, and the ratio of male to females dogs. House hold families were asked about the ages of their dogs, the age of the oldest dog, how the families disposed of their waste, and the type of toilet used by the family. Families were also asked if they would like to own more dogs?, and if they had observed unsupervised/un owned dogs in their communities.

\section{DOG HEALTH AND MORTALITY DATA}

Dog owning households were asked if dogs were registered, by what organization, if the dogs taken for treatment, and where they were treated. Dog owners were queried about rabies in their compound or surrounding areas. Respondents were also asked about the causes of death, if signs before death were similar to those of rabies, and how many dogs have died of rabies. All were asked about the age that recorded the highest mortality.

\section{DOG HUMAN RELATIOHSHIP}

Dog human relationship data were collected from respondents in all of the clusters. Respondents were asked if their dogs were restricted or confined, the number of dogs in the family, compound and per house hold, average life expectancy of dogs reared, average age range in the population, and number of births per year per female. House hold families were also asked about the ratio of male to female per birth, estimated human and dog population, the number of dogs in the neighborhood and percentage of dogs owned.

\section{RESULTS}

Table 1 represents the social economic data of respondents. A total of 900 dog owning households were interviewed between the 2 nd -4 th June, 2008, of which 512 (57\%) were males and $388(35 \%)$ female. Within these dog owning families, 583(65\%) were Christians and 317(35\%) Muslims. This figure is contrary to the Sierra Leone Muslim 
Atlas 2004, which show that about $75 \%$ of the population are Muslim and nearly 25\% are Christians. A breakdown of dog ownership in the study area shows revealed that $46 \%$ of households owned one dog, $29 \%$ owned two dogs, $16 \%$ owned four dogs and 9\% owned six dogs and above.

The ecology and habitat of dogs refers to the basic facilities dog owners provide for their animals, such as food, water and shelter. This is represented in Table 2. Seventy-four percent of the respondents (692) reported that they fed their dogs with kitchen left overs or household refuse, and allow them to feed on garbage. The majority of people had a source of income, but this is not reflected in their expenditure on feeding dogs. The majority of dog owners $88 \%(796)$ do not know how much they spend on their dogs per week, 7\% spend US\$3.0 a week and 3\% spend U\$6.0 .Data regarding the methods of feeding dogs reveal that $626(70 \%)$ partly feed their dogs whilst $17 \%$ of dogs in turn complements the effort of their owner by scavenging. Only $121(13 \%)$ fed their dogs daily in confinement, and of these, $579(64 \%)$ placed the food in plates and 321 (36\%) do not. During feeding, $69 \%$ provide tap water and $31 \%$ of dogs find a source of water for themselves. The majority of people $(66 \%)$ provide shelter for their dogs. However, one third of dog owners do not provide shelter $34 \%$ ( 307). The type of shelter provided include kennels $12 \%$ (109) but some of these dogs sleep on the streets in front of their compound 18\%(166),whilst the rest co-habit with their owners $625(69 \%)$.

In this study, $77 \%$ of dogs are owned by parents (father 420 and mother 275 ) and $17 \%$ by children. Dogs were owned mainly for security purposes $81 \%$ (731), which explains why a large percentage of the dogs were owned by parents and only few as pets for children A small percentage claimed to use dogs as food (0.4\%).Most of these dogs spend part of their time scavenging in garbage dumps and back yard for food, and return later after scavenging on these sites, whilst the others stay permanently on their own around these sites. Most people use dust bins to dispose of household refuse $53 \%$ (476), whilst $14 \%$ ( 125) throw house hold refuse directly into garbage dump, but $25 \%(221)$ use plastic bags. Most interviewed stated that they see stray dogs in their communities represented by $630(70 \%)$, as seen in Table 3.

Table 4 shows the canine and human relationship. Most residents in urban Freetown do not register their dogs $547(61 \%)$. People who have registered their dogs are those who received free rabies vaccination from SLAWS, represented by $55 \%$ (494). Most people refuse to take their dogs for rabies vaccination $45 \%$ (406). The non-compliance of people to vaccinate their dogs is due to their lack of knowledge about rabies, $74 \%$ (662), whilst those who know about it represent $26 \%$ (238).The life expectancy of dogs in study area varies from one to three years $40.0 \%(360)$. On average they can live for between four to seven years and above $44 \%$ (398).Most of the dogs were between the age of four to six 45\%(402), and one to three years 33\%(298)

\section{DISCUSSION}

After the cessation of hostilities, many people returned with few dogs, whilst others left their dogs behind with no one to care for them. These categories of dogs, combined with unsupervised dogs, led to an increase in dog populations in Freetown. Similar increases in dog population also occurred during the gulf war in Israel, when in January 1991, residents of metropolitan Tel Aviv area evacuated their home and abandoned their pets (Shimshony. A 1997).With decrease in human population and reduction in the number of garbage sites, ownerless and unsupervised dogs now had limited feeding areas, and were forced to move from house to house in search of food. They consume all available food that they come in contact with. Children are the most vulnerable category of people who easily predispose themselves to diseases transmitted by dogs. In some instances, these dogs eat with children from the same basin or lick their hands, wounds and mouth, thus increasing the possibility to contract the rabies virus. Children are thus at high risk to contract rabies and are serious victims of dog bite in Tanzania (Knobel et al 2005) and America (Overall 1998). Most of the respondents who rear dogs are between the age ranges of 1-64 years, representing the active population. It was however shown that the old (mature) people owned and rear more dogs (45.2\%) than their children (43.8\%). This is probably attributed to the fact that most parents rear dogs mainly for security reason, particularly so during the war. The low percentage of children involved in dog rearing is probably because most parents or homes do not rear dogs as pets. Active old people above 65 years also rear dogs maybe for companionship. It was also observed that men (56.9\%)were more involved in dog rearing than their female (43.1\%)counterparts. Men being the head of most household could be responsible for this. Aside from this, studies have revealed an association between adult gender composition of household and dog ownership. For example, in Kuwait, males were reported of having positive attitude towards dogs than females (AlFayez et al. 2003) whereas, for the semi rural communities in United Kingdom (Westgarth C et al.2007) and several North American and European countries (Bagley DK and Gonsman VL 2005), adult females were more associated with dog ownership. Although about $70 \%$ of the population in Sierra Leone are muslims, this was however, not reflected in the survey conducted where $64.8 \%$ of respondents were Christians and $35.2 \%$ were Muslims. Most Muslims interviewed indicated that they do notraise dogs because they are filthy and impure while others indicated that dogs shed their hair on praying mats hence, making their prayers invalid. Some however, maintained that they rear dogs due to security reasons. Religious beliefs about not wanting dogs are no longer effective in pastoral settlements, where livestock ownership encourages people to own more dogs (Foltz RC 2005). Owning dogs is not a major religious issue in Sierra Leone. Like many other countries in the world, such as Zimbabwe, there is religious tolerance regarding dog 
ownership The majority of the people interviewed was skilled $(71.7 \%)$ and are engaged in income generation activities whereas $13 \%$ are unskilled, and $15.4 \%$ are traders. This indicates that most dog owners have a source of income and have the capacity to feed their animals this is not however, reflected in the management of dogs as most people hardly budget for their animals and no special diet is provided for them. A number of American studies have shown relationship between dog ownership and household income (Wise and Kushman 1984). The majority (43.0\%) of the people haddependants between the age range 19 years (37.6\%). This shows that there is a high dependency rate, which explains why some families budget little money for their dogs. The majority of respondents interviewed (80.9\%) do not feed their dogs with canned food, which explain the status, type of relationship and care people in Freetown gives to dogs. Although the settlement of people in the city is most often based on social status, this was not shown by the people who feed their dogs with canned food. It was further revealed that most of the respondents use alternative sources of food (74.3\%) to feed their dogs, while only $(17.7 \%)$ feed their dogs with rice. This is due to the high increase in cost of rice which most people at the time of interview were not able to buy and feed their families. Most people (88.4\%) were not able to accurately calculate the cost of feeding their dogs per week and only (6.9\%) says they spend US\$3.00 per week. It can be seen that majority of respondent, spent little or almost nothing on their animals. This further explains that dog management such as feeding is not a priority to most families which has led to large numbers of strayed and unsupervised dogs roaming the streets of Freetown. Garbage dumps were present in some communities (43.3\%) which probably explain why some families pay less attention to feeding their dogs. The presence of garbage dumps in some of these communities, relief some families the burden of regularly feeding their dogs. This survey revealed that $42.9 \%$ of families gave free access to their dogs to feed on garbage dumps, whilst others could not. In Freetown, 17\% of respondents who own dogs manage them on free range basis. These categories of people do not feed their animals. The animals feed on garbage dumps and faeces. Butler (1998) reported that 53.3\% of house holdin rural Zimbabwewho do not have toilet, use the surroundings, therebyprovide human faeces as food for dogs. Others 69\% subject their dogs to semi-intensive management systems; partly feeding their dogs and the dogs find additional food from the surroundings. Semi intensive system of feeding has led to high number of street dogs in the city as most people using this system, often abandon their dogs and give little or no attention, thus causing the dogs to remain permanently in the surrounding garbage dumps. This type of behavior of unsupervised dogs is common in sub Saharan African countries like Kenya (Kitala et al. 1993a), Zambia (de Balogh et al. 1993a) and Tanzania (Clever land and Dye 1995a). Tap water is distributed throughout Freetown and has been a major source of drinking water $(68.8 \%)$ for all dogs. Most of the pipes connecting houses are old and dilapidated with many holes .These leaking pipes serve as a source of drinking water (21.1\%) for dogs. Drainages and potholes also serve as an alternative source (16.1\%) to the others and stream (4.0\%).Availability of drinking water becomes a major problem during the dry season due to lack of rainfall anddecrease inthe volume of water atGumadamthat supply Freetown. Survey results revealed that $69.4 \%$ of respondents co-habit with their dogs in their houses or within their compounds. Other category of respondents (17.1\%) allows their dogs to sleep outside their houses or compounds. These are mainly for security reasons and $34.1 \%$ dog owners do not know where their dogs sleep. Dog guarding is common in sub Saharan Africa, for example $45 \%$ of people in urban Nigeria keep dogs for guarding (Oboegbulem and Nwakonobi 1989), 70\% in Zimbabwe (Brooks 1990) and in pastoral communities in Africa (Macpherson and Wachira1997a). There was no significant difference between low-income and higher-income earners in terms of management of dogs in Freetown. Most respondents $(60.1 \%)$ do allow their dogs to interact with other dogs but $39.9 \%$ do not, for fear of transfer of diseases. Foggin (1990) confirmed that contact with rabid dogs was responsible for the $90 \%$ human rabies fatalities in Zimbabwe. Wandeler et al. (1993) affirm that frequent contact between unsupervised dogs and between unsupervised dogs and humans either during playing or mating are means through which rabies and other pathogens are transmitted between unsupervised dogs and human. Ealum et al. (2001) maintained that supervised dogs are also of public health concern because they are also potential carriers of zoonosis. Results show that $59.7 \%$ of respondent did not register their dogs with any organization. This makes it difficult for recognized institutions to accurately keep data on dogs. However, $38.9 \%$ of some respondent did register their dogs, of which $22.1 \%$ with veterinary clinic, $9.7 \%$ with Ministry of Health and Sanitation and $9.0 \%$ with private clinics. Those who claim to have registered their dogs hardly take them for treatment. About fifty-five percent of respondents vaccinated their dogs against rabies which was freely provided by Sierra Leone Animal Welfare Society and 45.5\% did not. Major causes of dog mortality in Freetown are due to lack of care and attention (33.3\%), diseases $(21.8 \%)$ and food $(10.3 \%)$. These causes are consistent with other parts of sub-Saharan Africa. Death rate is high among Puppies (28.6\%) and among mature dogs (32.1\%). This study revealed that life expectancy of dogs in Freetown is between three to seven years. This falls within the age range of dogs reared in Zimbabwe (Butler and Bingham 2000).

\section{CONCLUSION}

Results presented in this paper will help veterinary and public health officers, bilateral and multilateral agencies in the planning and implementation of rabies control programs in Sierra Leone and other rabies affected areas. The ratio of dogs to human is consistent with that of sub Saharan Africa .This implies that dog figures can be obtained and extrapolated against national population statistics to obtain more accurate and reliable dog numbers throughout the country. Obtaining accurate and reliable statistics on dogs will help in raising awareness and sensitization of the entire Sierra Leonean public. This will help in teaching ideal management practices to children at schools and among dog owning families, thereby making people to grow more interested in dog and animal management. Constant

How to Cite this Article: Mr. Roland Suluku, Mr. Ibrahim Abu-Bakarr, Mr. Jonathan Johnny, Prof F. Jonsyn-Ellis "Post-war Demographic and Ecological Survey of Dog Populations and Their Human Relationships in Sierra Leone. (A Case Study of Urban Freetown)" Science Journal of Agricultural Research \& Management, Volume 2012, Article ID sjarm-282, 7 Pages, 2012. doi: $10.7237 /$ sjarm/282 
attention and care given to dogs will help in control of rabies in Sierra Leone.

\section{Authors' Contributions}

Roland Suluku conceived the ideas, designed the questions with assistance of Dr Wanda and edited the questionnaire. R. Suluku, administered the questionnaire, analyzed the results and coordinated the entire process. All authors read and approved the final draft.

\section{ACKNOWLEDGEMENTS}

Thanks to the International Atomic Energy Agency (IAEA) who provided the fellowship, and through which the project was conceived. Professor Louis Nel and Dr Wanda Markoteer who introduced me to rabies, and my head of department, Dr Saidu Kanu, who always encouraged me to forge ahead with my ideas. We are grateful to the third year students of Agriculture General and Education, and first year honours Animal science that pretested and helped administer the questionnaireand Masters students of the same department who helped in the supervision. We are grateful to the engineering students in the School of Technology who did area measurement and calculation.Dr Momoh of the Department of Planning and Research and Development for introducing us to the statistical package for social scientists, and the entire community of Freetown, particularly the various police stations visited and the veterinary staff at Tower Hill.

\section{REFERENCES}

1. AL-Fayez G,Awadalla A, TemplerD,Arikawa H:Companion Animal Atitude and its Family Pattern in Kuwait, Society and Animals 2003,11:7-28

2. Bagley DK and GonsmanVL:Pet Attachment and Personality Type,Anthrozoos 2005,18:28-42

3. Boris M.Levinson (1969) Pet oriented child psychotherapy.

4. Brooks .R (1990) Survey of dog population of Zimbabwe and its level of rabies vaccination. Veterinary Record 127,592-596.

5. Butler J.R.A (1998) The ecology of domestic dogs. CanisFamiliaris in communual Lands of Zimbabwe. PhD thesis, University of Zimbabwe, Harare, Zimbabwe.

6. Butler JRA and Bingham,2000

7. Christine Mcgourty (2002). Making life easier (http;//en.wikipedia.org/wiki/Dog)

8. De BaloghK.K.I.M,Wandeler.A.I,Meslin .F.X(1993a):A Dog ecology study in an Urban and Semi-rural area of Zambia .Onderstepoort Journal of Veterinary Research 1993,60:437-443

9. De BaloghK.K.I.M,Wandeler.A.I,Meslin .F.X(1993b):A Dog ecology study in an Urban and Semi-rural area of Zambia .Onderstepoort Journal of Veterinary Research 1993,60:437-443

10. Ealum N L.et al (2001). Dog Zoonoses and public Health. Published by CABI Publishing.

11. Foggin.C.M (1988) Rabies and rabies-related viruses in Zimbabwe: Historical, virological and ecological aspects. PhDthesisUniversity of Zimbabwe,Harare,Zimbabwe
12. Foltz RC 2005: Animals in Islamic Tradition and Muslim Cultures.Oxford.Oneworld Publications; 2005. In Sierra Leone 19952001

13. Freetown city council by-laws (2009)?

14. Hatch.C ;Sneddon.J and G.Jalloh (2004) A descriptive study of urban rabies during the civil war?

15. Hart? a review of the relationship, In the Domestic Dog: Its Evolution, Behaviour and Interactions with people. Edited by :SerpellJ.CambridgeLA:Dogs as human Companions: University Press;1995:161-178

16. Kitala.pm,McDermont.J.J, Kyule.M.NandCathuma.J.M(1993a) features of dog ecology relevant to rabies spread in Machakos District, Kenya ondersteport journal of Veterinary RESEARCH 60,445-449

17. Kitala.pm,McDermont.J.J, Kyule.M.NandCathuma.J.M(1993b) features of dog ecology relevant to rabies spread in Machakos District, Kenya ondersteport journal of Veterinary RESEARCH 60,445-449

18. Knobel DL, Cleaveland S, Coleman PG, Fevre EM, Shaw A, and Zinsstag J, Meslin FX (2005):Re-evaluating the burden of rabies in Africa and Asia. Bulletin of the World Health Organization 2005,83:360-368 Pub Med Abstract

19. Knobel DL, Kaare M, Fevre E, and Cleaveland .S (2007): Dog rabies and its control. In rabies,2nd edition Edited by Jackson AC and Wunner WH London, Academic Press,2007:573-544

20. Macpherson CNL and Wachira TWM (1997a)Cystic echinococcus in Africa South of the Sahara. In Andersen, F.L Ouhelli, H. and Kachani, M.(eds) Compendium on Cystic Echinococcosis in Africa and in the Middle Eastern Countries With Special Reference to Morocco.Brighman Young University,Provo,Utah,pp.245-277

21. Macpherson, C.N.L. and Wachira T.W.M (1997b) Cystic echinococcus in Africa South of the Sahara. In Andersen, F.L Ouhelli, H. and Kachani, M.(weds) Compendium on Cystic Echinococcosis in Africa and in the Middle Eastern Countries With Special Reference to Morocco.Brighman Young University,Provo,Utah,pp.245-277

22. Morey ?and Darcy F,(2006) Burying key evidence: the social bond between dogs and people, Journal of Archaeological science 33 158175

23. Obogbulem ?and Nwakonobi ?(1989)Dogs, zoonoses and Public Health. Edited by Ealum, N.L, Macpherson, Francois-x, Meslin and Alexander I. Wandeler Page 43.

24. 26. Ouhelli et al? (1997) a Dogs, zoonoses and Public Health. Edited by Ealum, N.L, Macpherson, Francois-X, Meslin and Alexander I. Wandeler Page 45

25. Ouhelli et al ? (1997) b Dogs, zoonoses and Public Health. Edited by Ealum, N.L, Macpherson, Francois-x, Meslin and Alexander I. Wandeler Page 45

26. Overall K, (1998) When dog bite what you don't know can kill.DVM News magazine 1998 April.135-205.

27. S. Cleave land and Dye (1995a)Maintenance of micro parasites infecting several host species: rabies in the Serengeti,Parasitology $111,533-547$

28. 9. S. Cleaverland and Dye (1995b)Maintenance of micro parasites infecting several host species: rabies in the Serengeti,Parasitology 111,533-547

29. Sierra Leone police cooperate services department (2009),Annual crime report 1998-2001

30. Sierra Leone animal welfare association, profile (2009),

How to Cite this Article: Mr. Roland Suluku, Mr. Ibrahim Abu-Bakarr, Mr. Jonathan Johnny, Prof F. Jonsyn-Ellis “Post-war Demographic and Ecological Survey of Dog Populations and Their Human Relationships in Sierra Leone. (A Case Study of Urban Freetown)" Science Journal of Agricultural Research \& Management, Volume 2012, Article ID sjarm-282, 7 Pages, 2012. doi: 10.7237/sjarm/282 
31. Shimshony A,(1997):A epidemiology of emerging zoonoses in Isreal.Emerging infectious disease 3(2) 229-238,1997

32. Wandeler,A,I,Matter,H,C,Kappeler,A.andBudde,A(1993) The ecology of dogs and canine rabies: a selective rewiew, RevueScienfique et Technique de l'Office International des Epizooties 12,51-71.

33. Westgarth C, Pinchbeck G, Bradshaw J, Dawson S, Gaskell R, Christley R: Factors Associated With Dog Ownership and Contact With Dogs in a UKCommunity.BMC Veterinary Research 2007,3:5 Pub Med Abstract.

34. 34. Whitfield.J, 2005, Freetown forest vanishing environmental degradation follows war in SierrLeone. .News@nature.com http://www.bioedonline.org/news.cfm?art=462 11 September, 2003

35. World Health Organization.Geneva, (June, 1999) Guidelines for dog rabies control?

36. WHO/WSPA (1990a) Guideline for dog population management, Geneva, WHO

37. WHO/WSPA (1990b)Guideline for dog population management, Geneva, WHO

38. Wise J.K and Kushman JE: Pet Ownership by life group, Journal of the American Veterinary

How to Cite this Article: Mr. Roland Suluku, Mr. Ibrahim Abu-Bakarr, Mr. Jonathan Johnny, Prof F. Jonsyn-Ellis “Post-war Demographic and Ecological Survey of Dog Populations and Their Human Relationships in Sierra Leone. (A Case Study of Urban Freetown)" Science Journal of Agricultural Research \& Management, Volume 2012, Article ID sjarm-282, 7 Pages, 2012. doi: 10.7237/sjarm/282 